\title{
Neural Network of Plume and Spatter for Monitoring High-Power Disk Laser Welding
}

\author{
Xiangdong Gao ${ }^{1, \#}$, Yan Sun', and Seiji Katayama ${ }^{2}$
}

1 School of Electromechanical Engineering, Guangdong University of Technology, No.100 West Waihuan Road, Higher Education Mega Center, Panyu District, Guangzhou, China, 510006 2 Joining and Welding Research Institute, Osaka University, 11-1 Mihogaoka, Ibaraki, Osaka, Japan, 567-0047 \# Corresponding Author / E-mail: gaoxd666@126.com, TEL: +86-13711457326, FAX: +86-20-85215998

KEYWORDS: Disk-Laser welding, Plume, Spatter, BP neural network, Monitoring

Using multi-characteristic information fusion based on a BP (back propagation) NN (neural network) of the plume and spatters to monitor the high-power disk laser welding of type 304 austenitic stainless steel is presented. An ultraviolet and visible sensitive highspeed video camera was used to capture the dynamic images of laser welding plume and spatters during laser welding. The number and area of spatters, and the area, height, tilt angle and centroid of plume were calculated by using image processing technology and defined as the characteristic parameters of plume and spatters, which were used as inputs of the neural network. The weld bead width was considered as a parameter reflecting the welding status, which was used as output of the neural network. Relations of plume and spatters with laser welding status was established by a BP neural network and experimental results showed that the proposed method could effectively estimate the high-power disk laser welding status when the laser power ranged from $2 \mathrm{~kW}$ to $10 \mathrm{~kW}$.

\section{NOMENCLATURE}

$\mathrm{BP}=$ back propagation

$\mathrm{NN}=$ neural network

\section{Introduction}

Laser welding has been widely used in manufacturing process for its advantages such as flexibility, repeatability, high accuracy and especially very narrow heat-affected zone which results in minimal specimen distortions. ${ }^{1-3}$ Presence of welding plume affects laser material processing technology in that a large portion of energy emitted by the laser source is absorbed by the plume without hitting the specimen. Sensors can be used to detect the welding plume signal, and several methods have been investigated based on plume detection of the laser welding process. In the process of laser welding, a spectrometer was used to capture the emission spectrum of laserinduced plasma plume which has close relationship with the welding quality. ${ }^{4-6}$ During high-power disk laser welding, the high speed photography was used to measure the dynamic images of laser-induced plume and these digital images were transferred to the hue-saturationintensity color spaces. Plume features were extracted from the images and it was found that these features of plume could reflect the welding state. ${ }^{7}$ During deep penetration laser welding, high speed imaging was used to analyze the mechanisms of laser-induced plume. ${ }^{8}$ The plasma plume optical radiation emitted during $\mathrm{CO}_{2}$ laser welding of stainless steel samples was detected with a photodiode and analyzed under different process conditions. The discrete wavelet transform (DWT) could be used to decompose the optical signal into various discrete series of sequences over different frequency bands. ${ }^{9}$ However, certain relations between welding plume signal and welding quality had not been established.

Spatter involves the ejection of droplets of melt from a weld pool and is an occasional quality problem common to most welding processes. Sensors can be used to detect welding spatter, and it is found that welding spatter has close relationship with welding quality. In the process of laser welding, high-speed imaging was used to capture the dynamic images of laser welding spatters. By comparing the spatter information with molten pool, it is confirmed that there is a close relation between the spatter feature information and the welding quality. ${ }^{10,11}$ During arc welding, scanning electron microscopy and Xray mapping can be used to study the spatter phenomena. ${ }^{12}$ 
A multiple-optic sensing system based on two photodiode sensors and two visual sensors has been established for monitoring a highbrightness disk laser welding process. The proposed system provided a better understanding and accurate evaluation of laser welding process by quantitatively analyzing the features extracted from different optic sensors. $^{2}$ In order to further investigate the relations of plume and spatters with laser welding, we used an ultraviolet and visible sensitive high-speed video camera to capture the dynamic plume and spatter images, and study the BP neural network models to reveal the relationship between plume, spatter characteristics and welding quality. The number, area of spatters, and the area, height, tilt angle and the centroid of plume were calculated by using the image processing technology and defined as the characteristic parameters of spatters and plume. The weld bead width was considered as a parameter reflecting the welding stability. The defined plume and spatter characteristic parameters were considered as the model inputs to calculate weld bead width based on a BP neural network. Influence of laser powers on the weld bead width was investigated, and it is found that the defined plume and spatter characteristic parameters have relations with the laser powers. Especially, these plume and spatter characteristic parameters can be applied to estimate the weld bead width variations. The mean errors between the actual bead width and the model training output were not more than $0.2 \mathrm{~mm}$ when laser power ranged from $2 \mathrm{~kW}$ to $10 \mathrm{~kW}$.

\section{Experimental Setup}

Experimental specimen material was type 304 austenitic stainless steel plates of $10 \mathrm{~mm}$ in thickness. The experimental system, shown in Fig. 1, consisted of high-power disk laser welding equipment, a Panasonic 6-axis robot, an imaging collecting system and the shielding gas (Argon) whose flowing rate was $40 \mathrm{~L} / \mathrm{min}$. The diameter of focused laser beam was $480 \mu \mathrm{m}$ and the wavelength of disk laser was $1030 \mathrm{~nm}$. Laser welding speed was set to $3 \mathrm{~m} / \mathrm{min}$ and the laser power ranged from $2 \mathrm{~kW}$ to $10 \mathrm{~kW}$. To monitor the behavior of plume and spatters, a high-speed camera equipped with an ultraviolet and visible sensing filter $(320-750 \mathrm{~nm})$ was set up at the position perpendicular to the welding direction. The camera frame rate was $2000 \mathrm{fps}$ and the image resolution was 512 pixels $\times 512$ pixels.

A laser welding process and an ultraviolet image of plume and

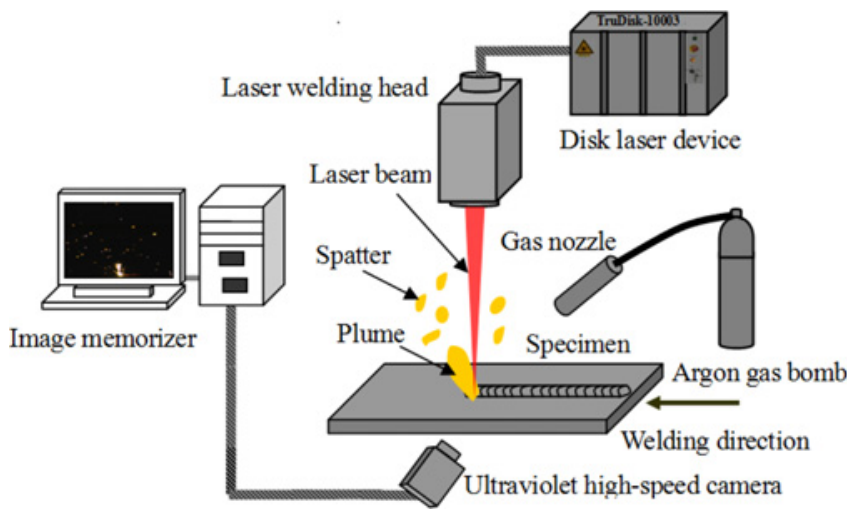

Fig. 1 Schematic diagram of multiple optical sensing of disk laser welding spatters are shown in Fig. 2. When a laser beam with high laser intensity is incident on the specimen, the irradiated material is vaporized, and a strong recoil pressure will push the molten metal aside, then a keyhole is formed in the molten pool. Laser-induced plume exists both inside the keyhole and above the specimen surface. The plume that escapes from keyhole can block and reflect or defocus the laser beam, resulting in insufficient penetration or irregular weld shape or contamination of beam delivery optics. Spatter, which is the ejection of melt droplets from a molten pool, is a general defect observed in all welding process. Molten pool ejection in the form of spatter will result in an unsteady appearance of weld seam. The ultraviolet image shown in Fig. 2 contains much information of plume and spatters.

\section{Analysis of Plume and Spatter Dynamic Characteristics}

To analyze the plume and spatter dynamic characteristics, we firstly investigated the effect of laser power on the welding plume and spatters. Fig. 3(a) shows a plume and spatter image captured by an ultraviolet and visible high-speed camera when the laser power was $8 \mathrm{~kW}$. It was first turned into grayscale image, and then Wiener filtering was used to eliminate the image noises. After binarization processing and morphological opening operation, the image after deleting the areas which were less than 100 pixels is a binary plume image shown in Fig. 3(b). The binary spatter image shown in Fig. 3(c) could be obtained by a method that the image after binarization processing was subtracted by the binary plume image. Plume and spatter characteristics were defined and calculated. The centroid $\left(p_{x}\right.$ and $\left.p_{y}\right)$, area $\left(p_{A}\right)$, tilt

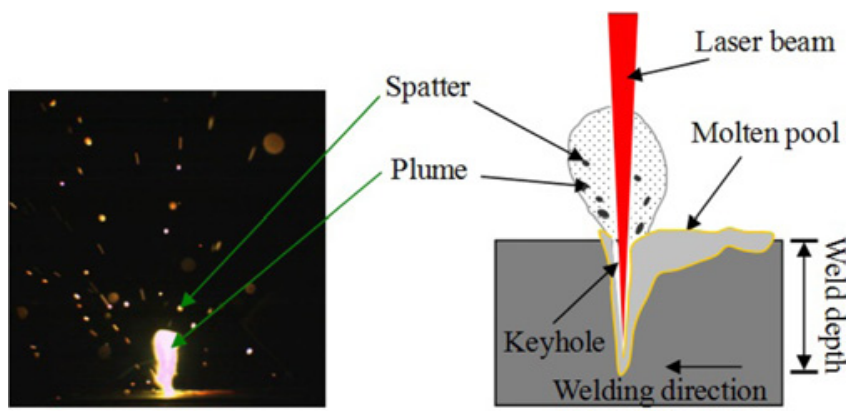

Fig. 2 Schematic diagram of laser welding process and image of plume and spatters

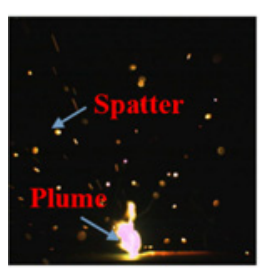

(a)

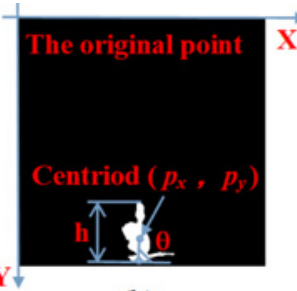

(b)

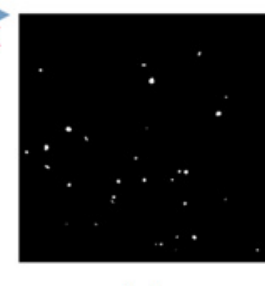

(c)
Fig. 3 A plume and spatter image captured by ultraviolet and visible sensitive high-speed camera when laser power was $8 \mathrm{~kW}$ and welding speed was $3 \mathrm{~m} / \mathrm{min}$ (calibration value $6.67 \mathrm{pixel} / \mathrm{mm}$ ). (a) A plume and spatter color image. (b) A binary plume image. (c) A binary spatter image 


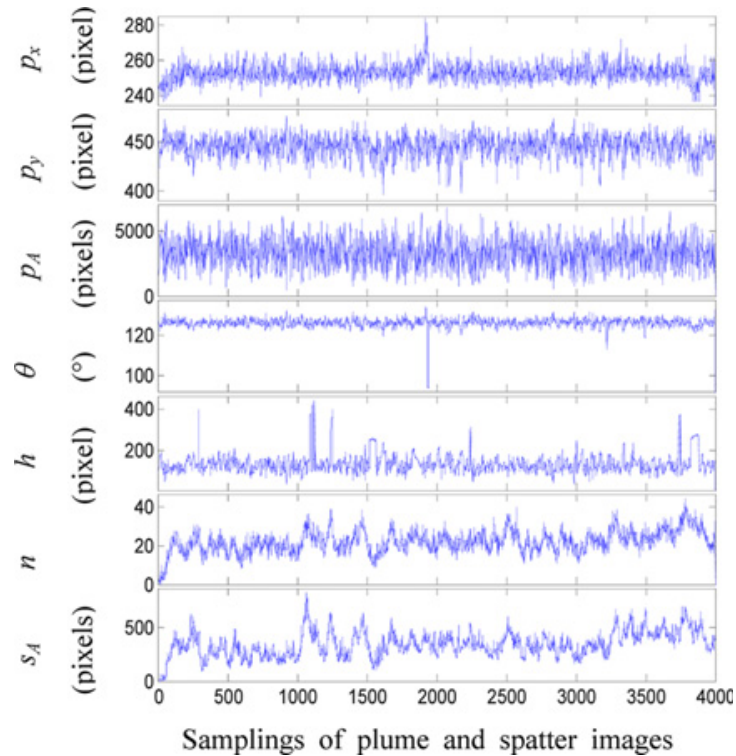

Fig. 4 Plume and spatter configuration parameters during disk laser welding of type 304 austenitic stainless steel plates when the laser power was $2 \mathrm{~kW}$ and the welding speed was $3 \mathrm{~m} / \mathrm{min}$

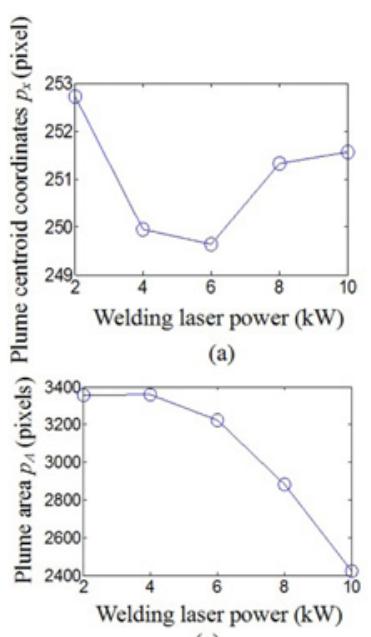

(c)

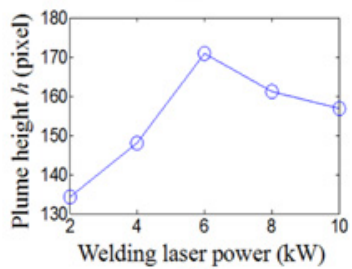

(e)

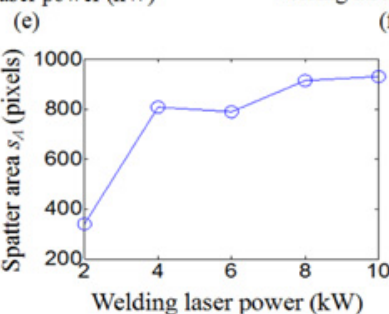

(g)

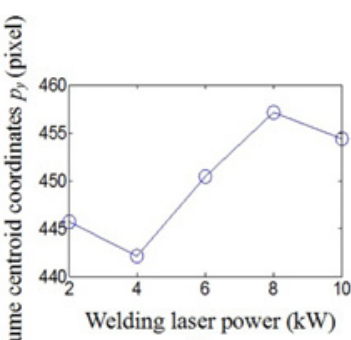

(b)
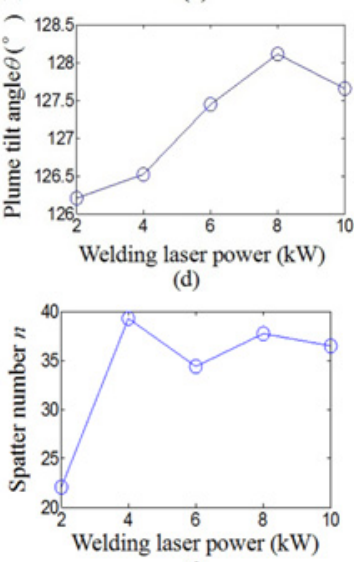

(f)
Fig. 5 Fluctuating tendency of plume and spatter configurations when laser power changed from $2 \mathrm{~kW}$ to $10 \mathrm{~kW}$ (calibration value 6.67 pixel $/ \mathrm{mm}$ ). (a) Plume centroid coordinates $p_{x}$. (b) Plume centroid coordinates $p_{y}$ (c) Plume area $p_{A}$. (d) Plume tilt angle $\theta$. (e)Plume height $h$. (f) Spatter number $n$. (g) Spatter area $s_{A}$ angle $(\theta)$ and height $(h)$ of a plume, and the number $(n)$ and area $\left(s_{A}\right)$ of spatters were defined as the plume and spatter configuration parameters. Fig. 4 shows the parameter variations and totally 4000 plume and spatter images were analyzed when the laser power was $2 \mathrm{~kW}$. The mean values of plume and spatter configuration parameters are shown in Fig. 5, where the laser power ranged from $2 \mathrm{~kW}$ to $10 \mathrm{~kW}$. When the laser power increased from $2 \mathrm{~kW}$ to $4 \mathrm{~kW}$, more laser energy was incident to the specimen, resulting in more spatters and plume, and it can be seen that the parameters $n, h$, and $s_{A}$ increased rapidly, but $p_{y}$ decreased. With laser power increasing, the intensity of plume and spatter increased, the incident laser energy also lost more, the parameter $p_{A}$ decreased sharply, $p_{y}$ and $h$ increased. Moreover, the parameters $h$ and $p_{x}$ have same change trend. When $h$ increased, the plume swang to the left due to shielding gas blowing, resulting in $p_{x}$ decreasing. In order to get the statistical significance of defined laser welding characteristics, standard deviations of these parameters were calculated shown in Fig. 6. It can been seen that the parameters $p_{x}, p_{y}$ and $s_{A}$ changed more severely with increase of laser power. Apparently, plume and spatter parameters has close relationship with laser power
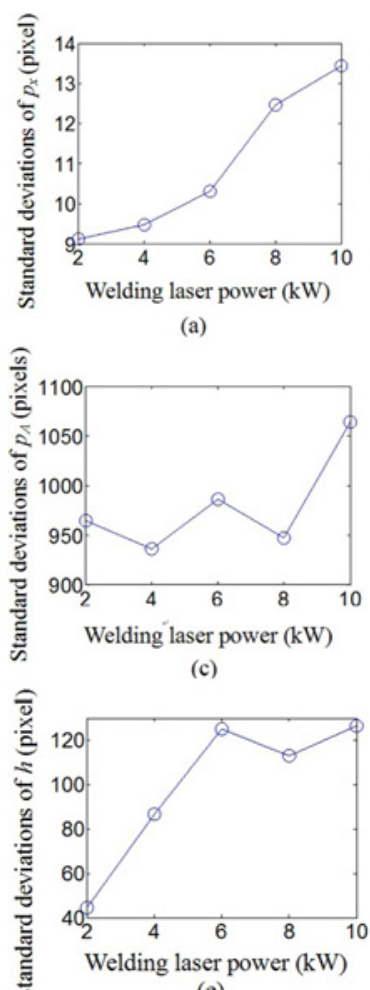

(e)

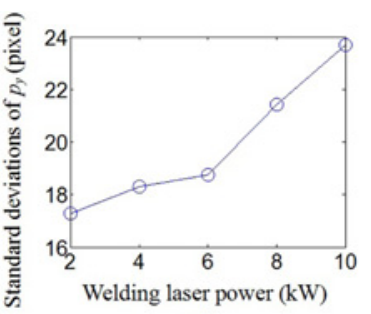

(b)

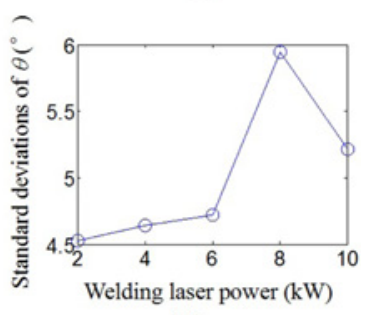

(d)

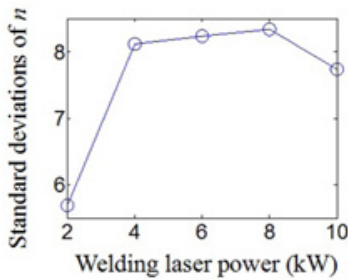

(f)

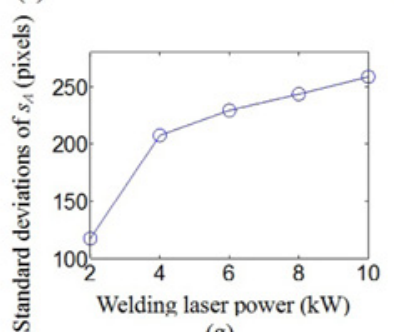

Fig. 6 Standard deviations of plume and spatter configurations when laser power changed from $2 \mathrm{~kW}$ to $10 \mathrm{~kW}$ (calibration value $6.67 \mathrm{pixel} / \mathrm{mm}$ ). (a) Plume centroid coordinates $p_{x}$. (b) Plume centroid coordinates $p_{y}$ (c) Plume area $p_{A}$. (d) Plume tilt angle $\theta$. (e)Plume height $h$. (f) Spatter number $n$. (g) Spatter area $s_{A}$ 
and welding status.

When the laser powers ranged from $2 \mathrm{~kW}$ to $8 \mathrm{~kW}$, the specimen were incompletely penetrated. Whereas laser power was strong enough to reach $10 \mathrm{~kW}$, the specimen was full of penetration and some places appeared pits because melted area could not be filled timely when liquid metal flowed to the bottom. The keyhole penetrated specimen so that quite qualitative change of welding status taken place and welding characteristic parameters changed suddenly at the same time. It was found that parameters $p_{y}$ and $\theta$ began to decrease when specimen was penetrated. The changes of parameters $\theta$ and $n$ slowed down at the same time. Weld bead appearance of specimen surface and weld bead width of top surface under different laser power conditions are shown in Fig. $7 .^{13}$

\section{BP Neural Network Model}

BP neural network is one of the most maturely studied neural network, which has good self-learning, self-adapting, robustness and generalization ability. ${ }^{14-16}$ A three-layer BP neural network can approach any non-linear functions with any precision. Up to now, BP neural network has been widely applied in many fields such as pattern recognition function approximation and image processing, and it is a simply gradient descent method designed to minimize the total error (or mean error) of output computed by the network. The effectiveness of this kind of model was demonstrated when the laser power was $10 \mathrm{~kW}$ and the welding speed was $4.5 \mathrm{~m} / \mathrm{min}^{17}$

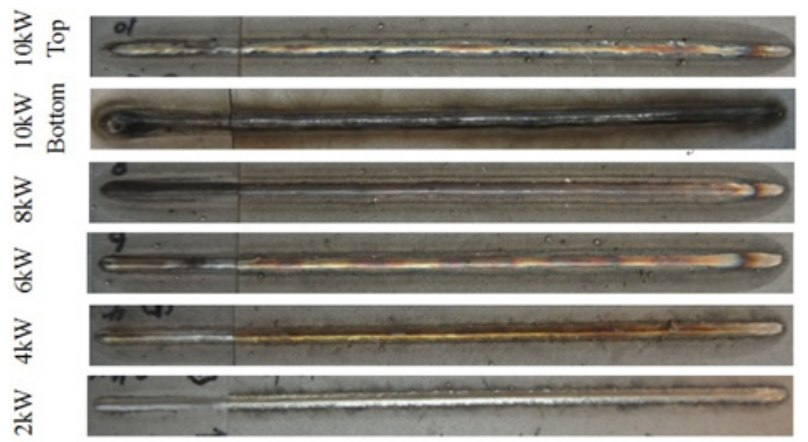

(a)

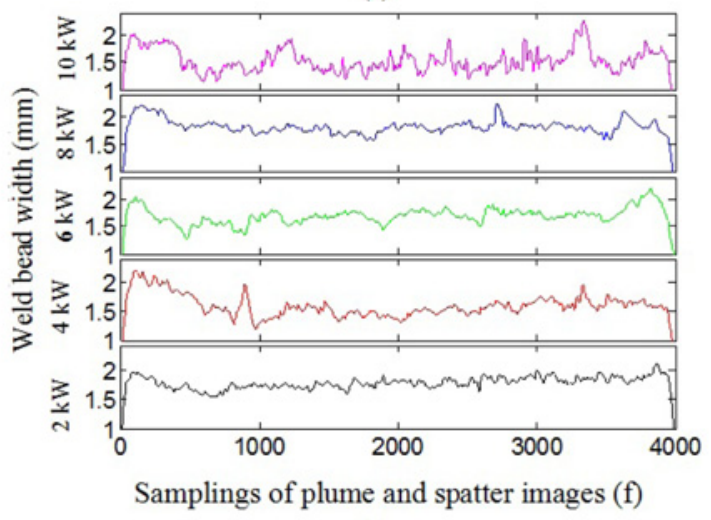

(b)

Fig. 7 Top view of specimen and weld bead width when laser power ranged from $2 \mathrm{~kW}$ to $10 \mathrm{~kW}$ (a) Surface appearance (b) Weld bead width $^{13}$
Here, a three layer BP neural network shown in Fig. 8 was designed as a model for monitoring high disk laser welding process. The weld bead width of specimen surface could be considered as a parameter reflecting the welding quality. ${ }^{18}$ Plume and spatter configuration parameters $\left(x_{1}, x_{2}, \ldots, x_{7}\right)$ were considered as inputs to calculate theoretical weld bead width and $1501-2500^{\text {th }}$ groups of characteristic parameters were selected as the test sets and the others as the training sets. Suppose there are $n(n=7)$ inputs and $m(m=1)$ outputs in the network, and $s$ neurons in the hidden layer, the output of hidden layer is $b_{j}$, the threshold value of hidden layer is $\theta_{j}$, the threshold value of output layer is $\theta_{k}$. Sigmoid function $f_{1}$ and $f_{2}$ are used as the transfer functions of the hidden layer and the output layer, respectively. The weight from the input layer to the hidden layer is $w_{i j}$, and the weight from the hidden layer to the output layer is $w_{j k}$, Then we can get the neural network output $y_{k}$, which is considered as a theoretical output of weld bead width. The desired neural network output is actual weld bead width $y_{w}$, and the output of $j^{\text {th }}$ neuron of hidden layer is

$$
b_{j}=f_{1}\left(\sum_{i=1}^{n} w_{i j} x_{i}-\theta_{j}\right)
$$

where $i=1,2, \ldots, 7 ; j=1,2, \ldots, s$.

The neural network output $y_{k}$ can be calculated by using following equation

$$
y_{k}=f_{2}\left(\sum_{j=1}^{s} w_{j k} b_{j}-\theta_{k}\right)
$$

where $j=1,2, \ldots, s ; k=1$.

The transfer function is

$$
f_{1}=f_{2}=f(x)=1 /(1+\exp (-x))
$$

A BP neural network was built, and the characteristic parameters and weld bead width related to $1-1500^{\text {th }}$ and $2501-4000^{\text {th }}$ groups of data when the laser power changed from $2 \mathrm{~kW}$ to $10 \mathrm{~kW}$ were selected to train the neural networks. The rest 1000 groups of data, when the laser power was a certain value, were selected to test the neural network. The goal of training was set to be $4 \times 10^{-5} \mathrm{~mm}$, the learning rate was set to be 0.001 , and the training step was set to be 2000 . To make the NN training error minimum and obtain the best $\mathrm{NN}$ weights, the $\mathrm{NN}$ training program was run repeatedly and three NNs with different $s$ $(s=5,6,7)$ were trained. It was found that the network with a hidden layer of 6 neurons yielded the smallest mean error. The trained BP neural network weights and threshold values with 6 neurons of hidden layer are shown in Eq. (4)-(7).

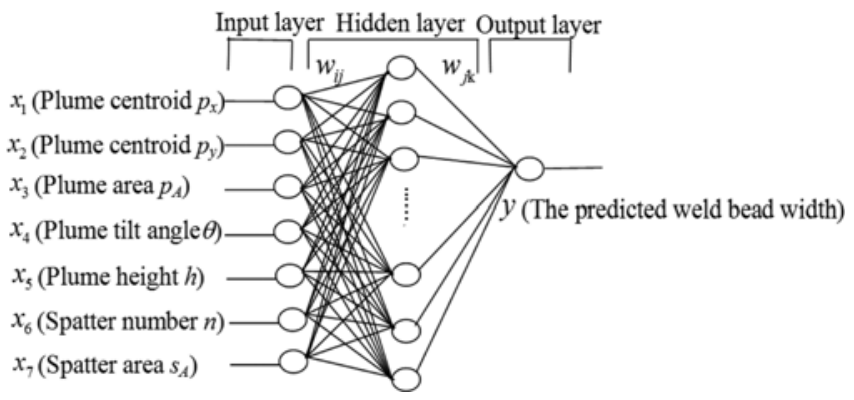

Fig. 8 BP neural network for predicting weld bead width based on plume and spatter characteristics of disk laser welding 


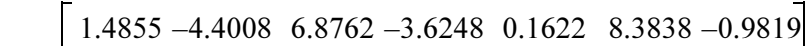

$$
\begin{aligned}
& \begin{array}{llllll}
1.5811 & -3.4196 & 6.3961 & -4.9038 & 0.3262 & -6.1628-1.6292
\end{array} \\
& w_{i j}=\left|\begin{array}{llllll}
-0.6454 & 4.2962 & 0.4729 & -7.9445 & 0.5520 & -6.3964-5.7571 \\
0.3798 & 0.4160 & -3.4589-1.1310 & 0.0248 & -2.7411-1.9910
\end{array}\right| \\
& 0.3798 \quad 0.4160-3.4589-1.1310 \quad 0.0248-2.7411-1.9910 \\
& \begin{array}{llllll}
5.4116 & -3.0557 & 0.7344 & 4.3578 & -0.9094-1.8532 & 4.1103
\end{array} \\
& \begin{array}{llllllll}
3.3178 & 2.0942 & 9.5242 & 1.3128 & 0.8981 & -7.8077 & 15.1208
\end{array}
\end{aligned}
$$

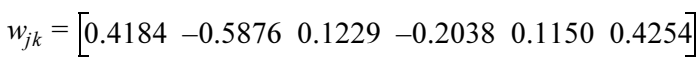

$$
\begin{aligned}
& \theta_{j}=\left[\begin{array}{llllll}
6.0741 & -8.1041 & -3.5061 & 1.6580 & 2.5613 & -1.0435
\end{array}\right]^{T} \\
& \theta_{k}=[-0.1004]
\end{aligned}
$$

\section{Monitoring of Laser Welding Status using BP Neural Network}

The relation of plume and spatters with weld bead width has been established by a BP neural network. To test the effectiveness of NNs, the three trained $\mathrm{NN}$ were examined. The testing error $e$ of $\mathrm{NN}$ is

\begin{tabular}{|c|c|c|c|}
\hline 1 & Laser power(kW) & $r(\mathrm{~mm})$ & Standard deviation of $e$ \\
\hline \multirow{5}{*}{$s=5$} & 2 & 0.0544 & 0.0621 \\
\hline & 4 & 0.1996 & 0.0885 \\
\hline & 6 & 0.0788 & 0.1042 \\
\hline & 8 & 0.0720 & 0.0924 \\
\hline & 10 & 0.1502 & 0.1501 \\
\hline \multirow{5}{*}{$s=6$} & 2 & 0.0531 & 0.0663 \\
\hline & 4 & 0.1987 & 0.0992 \\
\hline & 6 & 0.0882 & 0.1137 \\
\hline & 8 & 0.0624 & 0.0773 \\
\hline & 10 & 0.1560 & 0.1565 \\
\hline \multirow{5}{*}{$s=7$} & 2 & 0.0513 & 0.0606 \\
\hline & 4 & 0.1864 & 0.1026 \\
\hline & 6 & 0.0911 & 0.1171 \\
\hline & 8 & 0.0689 & 0.0845 \\
\hline & 10 & 0.1571 & 0.1570 \\
\hline
\end{tabular}
depicted by Eq. (8), and the mean absolute testing error $r$ of $\mathrm{NN}$ is calculated by Eq. (9), in which $e_{p}$ refers to the $\mathrm{p}^{\text {th }}$ testing error $e$ of 1000 groups of testing set. Table 1 shows the testing results of $\mathrm{NN}$ with different $s(s=5,6,7)$ and different laser powers.

Table 1 Neural network testing results with different $s$ neurons in the hidden layer when laser power changed from $2 \mathrm{~kW}$ to $10 \mathrm{~kW}$

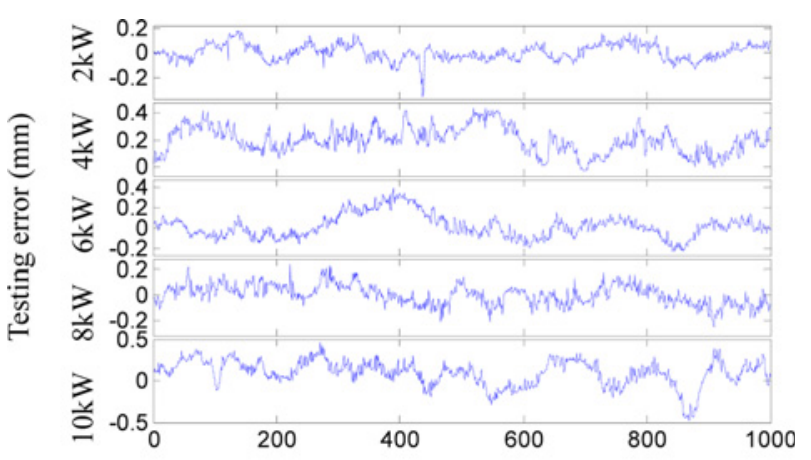

Samplings of plume and spatter images (f)

Fig. 9 Neural network testing error when laser power ranged from $2 \mathrm{~kW}$ to $10 \mathrm{~kW}$

$$
\begin{gathered}
e=y_{k}-y_{w} \\
r=\left(\sum_{p=1}^{1000} a b s\left(e_{p}\right)\right) / 1000
\end{gathered}
$$

Fig. 9 gives the neural network testing error curves which corresponds to laser powers $2 \mathrm{~kW}, 4 \mathrm{~kW}, 6 \mathrm{~kW}, 8 \mathrm{~kW}$ and $10 \mathrm{~kW}$. The maximum values of $e$ were $0.3648 \mathrm{~mm}, 0.4434 \mathrm{~mm}, 0.3893 \mathrm{~mm}$, $0.2445 \mathrm{~mm}$ and $0.4784 \mathrm{~mm}$, respectively. The minimum values of $e$ were close to zero. It could be seen that the mean testing error of BP neural network was not more than $0.2 \mathrm{~mm}$. Therefore, we can draw the conclusion that multi-characteristic fusion based on a BP neural network is an effective method to monitor welding status.

\section{Conclusions}

In the disk laser welding of type 304 austenitic stainless steel plates, an ultraviolet and visible sensitive high-speed video camera was used to capture the plume and spatter dynamic images, and the characteristic parameters of spatter and plume were defined. It has been found that plume and spatter parameters have close relationship with the laser power and the welding status. When the laser power increased from $2 \mathrm{~kW}$ to $4 \mathrm{~kW}$, the specimen was vaporized more intensely and welding status changed, and then plume and spatters characteristics changed as well. With the density of plume and spatter increased, the incident laser energy lost more, the plume area decreased sharply, plume vertical coordinate and plume height increased. Moreover, the parameters of plume height and plume horizontal coordinate have same change trend. Whereas laser power was strong enough to reach $10 \mathrm{~kW}$, the keyhole penetrated specimen so that quite qualitative change of welding status took place and welding characteristic parameters changed suddenly at the same time. It is confirmed that the welding status, represented by the weld bead width, can be evaluated by the plume and spatter characteristics. A BP neural network trained by 15000 groups of plume and spatter characteristics under different laser powers could monitor welding status when laser power changed from $2 \mathrm{~kW}$ to $10 \mathrm{~kW}$. Experimental results show that the BP neural network of plume and spatter is an effective method to monitor the laser welding status.

\section{ACKNOWLEDGEMENT}

This work was partly supported by the National Natural Science Foundation of China (Grant No. 51175095), the Natural Science Foundation of Guangdong Province, China (Grant No. 10251009001000001), the Guangdong Provincial Project of Science and Technology Innovation of Discipline Construction, China (Grant No. 2013KJCX0063) and the JSPS Invitation Fellowship Programs for Research in Japan.

\section{REFERENCES}

1. Kim, J. W. and Kim, C. G., "Design of a Laser Welded Thin Metal Tube Structure Incorporating Welding Distortion and Residual Stress,” Int. J. Precis. Eng. Manuf., Vol. 11, No. 6, pp. 925-930, 2010. 
2. You, D., Gao, X., and Katayama, S., "Multiple-Optics Sensing of High-Brightness Disk Laser Welding Process," NDT \& E International, Vol. 60, pp. 32-39, 2013.

3. Gao, X., You, D., and Katayama, S., "Seam Tracking Monitoring based on Adaptive Kalman Filter Embedded Elman Neural Network during High-Power Fiber Laser Welding," IEEE Transactions on Industrial Electronics, Vol. 59, No. 11, pp. 4315-4325, 2012.

4. Sabbaghzadeh, J., Dadras, S., and Torkamany, M., "Comparison of Pulsed Nd: YAG Laser Welding Qualitative Features with Plasma Plume Thermal Characteristics," Journal of Physics D: Applied Physics, Vol. 40, No. 4, pp. 1047-1051, 2007.

5. Mirapeix, J., García-Allende, P. B., Cobo, A., Conde, O. M., and López-Higuera, J. M., "Feasibility Study of Imaging Spectroscopy to Monitor the Quality of Online Welding," Applied Optics, Vol. 48, No. 24, pp. 4735-4742, 2009.

6. Liu, W., Liu, S., Ma, J., and Kovacevic, R., "Real-Time Monitoring of the Laser Hot-Wire Welding Process," Optics \& Laser Technology, Vol. 57, pp. 66-76, 2014.

7. Gao, X. D., Wang, R. L., Long, G. F., and Katayama, S., "Study of Characteristics of Plume based on Hue-Saturation-Intensity during High-Power Disk Laser Welding," Interdisciplinary Physics and Related Areas of Science and Technology, Vol. 61, No. 14, p. 148103, 2012.

8. Brock, C., Hohenstein, R., and Schmidt, M., "Mechanisms of Vapour Plume Formation in Laser Deep Penetration Welding," Optics and Lasers in Engineering, Vol. 58, pp. 93-101, 2014.

9. Sibillano, T., Ancona, A., Rizzi, D., Lupo, V., Tricarico, L., and Lugarà, P. M., "Plasma Plume Oscillations Monitoring during Laser Welding of Stainless Steel by Discrete Wavelet Transform Application,” Sensors, Vol. 10, No. 4, pp. 3549-3561, 2010.

10. Zhang, M., Chen, G., Zhou, Y., Li, S., and Deng, H., "Observation of Spatter Formation Mechanisms in High-Power Fiber Laser Welding of Thick Plate," Applied Surface Science, Vol. 280, pp. 868-875, 2013.

11. You, D., Gao, X., and Katayama, S., "Visual-Based Spatter Detection during High-Power Disk Laser Welding," Optics and Lasers in Engineering, Vol. 54, pp. 1-7, 2014.

12. Molleda, F., Mora, J., Molleda, J., and Mora, E., "The Importance of Spatter Formed in Shielded Metal Arc Welding," Materials Characterization, Vol. 58, No. 10, pp. 936-940, 2007.

13. Gao, X. and Sun, Y., "Monitoring of High-Power Disk Laser Welding of Type 304 Austenitic Stainless Steel based on Keyhole Dynamic Characteristics," Insight-Non-Destructive Testing and Condition Monitoring, Vol. 56, No. 6, pp. 312-317, 2014.

14. Ding, S. F., Su, C. Y., and Yu, J. Z., "An Optimizing BP Neural Network Algorithm based on Genetic Algorithm," Artificial Intelligence Review, Vol. 36, No. 2, pp. 153-162, 2011.

15. Wang, P., Zhu, L., Zhu, Q. J., Xiaoli, J., Haitao, W., et al, “An
Application of Back Propagation Neural Network for the Steel Stress Detection based on Barkhusen Noise Theory," NDT \& E International, Vol. 55, pp. 9-14, 2013.

16. Haykin, S. S., "Neural Networks and Learning Machines," Pearson Education Upper Saddle River, 2009.

17. Wang, T. and Gao, X. D., "Prediction of Molten Pool Width with Artificial Neural Network Model," Advanced Materials Research, Vol. 482-484, pp. 2210-2213, 2012.

18. Gao, X. D. and Zhang, Y. X., "Prediction Model of Weld Width during High-Power Disk Laser Welding of 304 Austenitic Stainless Steel,” Int. J. Precis. Eng. Manuf., Vol. 15, No. 3, pp. 399-405, 2014. 